\section{Reducing futile attempts at resuscitation}

\author{
John Launer
}

A recent review in the $\mathrm{BMJ}$ has drawn attention to major concerns about 'Do Not Attempt Cardio-Pulmonary Resuscitation' (DNACPR) forms. ${ }^{1}$ One of these concerns is with the distressing number of deaths that are surrounded by futile attempts at cardio-pulmonary resuscitation (CPR). Such attempts occur for a number of reasons. Some patients with terminal illnesses, or who are elderly and frail, do not have a form, perhaps because their doctors were too busy or never got round to raising the issue. Other patients may have deteriorated very soon after admission, or more quickly than anyone expected, so that no-one had a chance to discuss their wishes with them in advance. A few patients may have refused consent to having DNACPR on their records because of their beliefs, in spite of having diseases likely to lead to death. In all these circumstances, doctors who are called at the time of death will typically feel they have no authority to withhold CPR, or they fear the legal risks of doing so - in spite of knowing that what they are doing is pointless. Their fear is understandable. In the UK, the guidance from the Resuscitation Council states that should be an initial presumption in favour of $\mathrm{CPR}^{2}$ and regulators continue to impose sanctions on clinicians who decided not to resuscitate patients who had been dead for some time ${ }^{3}$

There do not appear to be any studies of how often such attempts take place, but narrative accounts of them are common. ${ }^{45}$ The injuries that patients sustain during such attempts include broken ribs, tracheal damage from intubation, and extensive bruising - along with a profound loss of personal dignity. Although patients in these circumstances are unlikely to be conscious of these effects, one physician has suggested that futile CPR may be tantamount to assault and might constitute torture under the European Convention on Human Rights ${ }^{6}$ Whether or not this is the case, families who witness these attempts, or the results of them, can be traumatised. Conversely, if families happen to be absent during a failed attempt, they may never be

Correspondence to Dr John Launer, Health Education England, Stewart House, London WC1B 5DN, UK; john. launer@hee.nhs.uk told of these injuries, raising an equally serious ethical concern. The effects of such failed attempts on the doctors and other staff who carry them out can also be harrowing. ${ }^{\text {? }}$

Some of the remedies for this state of affairs are clear. Every consultant should emphasise the importance of DNACPR forms and encourage teams to make them a priority. Educators can train junior doctors about how to hold more candid conversations with patients and families so they make more informed decisions. Hospitals should monitor the frequency of failed attempts at resuscitation and review these to see how many could have been avoided. Beyond these practical changes, however, there is clearly a need for an alteration in mind-set about the nature of resuscitation and of death itself.

\section{CARDIAC ARREST AND ORDINARY DYING}

One good starting point is to recognise that hospitals nowadays are mostly full of people with multiple comorbidities who at some point are going to die from these, even if the date cannot be predicted with accuracy. When they do so, their hearts will stop. This kind of ordinary dying (which most of us are likely to undergo) is entirely different from cardiac arrest as commonly understood, and for which CPR procedures are designed. ${ }^{8}$ Ageing patients who are approaching such deaths need a compassionate explanation that chest compressions and electric shocks will never restore their failing organs, and the purpose of a DNACPR document is simply to spare themselves the indignity of such acts. As many doctors have argued, it is then far more important for the conversation to focus on advance care planning to ensure that patients' remaining years, months or weeks are spent in the way they would wish. ${ }^{9}$

In the same spirit, we should encourage medical students and junior doctors to recognise $\mathrm{CPR}$ for what it is: a medical intervention with clear indications and contra-indications, just like any other treatment. It has a reasonable success rate in isolated cardiac arrest, but a 'miserable' one in deaths arising from other causes. ${ }^{10}$ Just as no-one would consider prescribing chemotherapy for ischaemic heart disease, it is unreasonable in most instances to administer CPR in patients who are dying as a result of cancer or other non-cardiac causes.

There are several standard tools for assessing the likelihood of a successful resuscitation. Although none of these are sensitive enough in themselves to determine CPR decisions ${ }^{11}$ they can be combined with other measures including clinical frailty ${ }^{12}$ to aid discussions with patients and families. Some hospitals have already replaced DNACPR forms with one offering the positive option 'Allow Natural Death' (AND) ${ }^{13}$ Other alternatives include the 'Universal Form of Treatment Options', which has been shown to reduce the risk of staff misinterpreting DNACPR as a reason for withholding interventions that could benefit patients. ${ }^{14}$ Logically, it might also make sense to replace the use of DNACPR forms with a positive recommendation for a minority of patients only ('suitable for cardiac compression and electric shock if required').

Finally, a patient's wishes in relation to resuscitation are not legally overriding, So long as patients have been involved in the decision-making process, doctors are not bound to carry out unnecessary and ineffective treatment in relation to CPR, any more than if someone demands any other kind of treatment that is inappropriate and harmful for their condition. ${ }^{15}$ Instead of regarding the issue of DNACPR as a legal hurdle, it is time to move on to seeing it as an opportunity to have the kind of conversations with patients and their families that actually need to take place, and for clinicians and regulators to make the right professional judgements when this has not occurred.

\section{Competing interests None declared.}

Provenance and peer review Commissioned; internally peer reviewed.

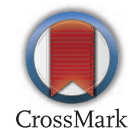

To cite Launer J. Postgrad Med J 2017;93:239-240.

Postgrad Med J 2017;93:239-240.

doi:10.1136/postgradmedj-2017-134944

(C) Article author(s) (or their employer(s) unless otherwise stated in the text of the article) 2017. All rights reserved. No commercial use is permitted unless otherwise expressly granted.

\section{REFERENCES}

1 Fritz Z, Slowther AM, Perkins GD. Resuscitation policy should focus on the patient, not the decision. BMJ 2017;356:j813.

2 Decisions relating to cardiopulmonary resuscitation $3^{\text {rd }}$ edition ( $1^{\text {st }}$ revision). London: British Medical 
Association, Resuscitation Council and Royal College of Nursing, 2016. https://www.resus.org.uk/dnacpr/ decisions-relating-to-cpr/ (accessed 13 Mar 2017).

3 Nursing and Midwifery Council. Conduct and competence committee substantive hearing. 2017 www.nmc.org.uk/globalassets/sitedocuments/ ftpoutcomes/2017/january-2017/reasons-kendallcccsh-048388-20170109.pdf (accessed 13 Mar 2017).

4 Mawer C. CPR can be futile - and is sometimes worse. BMJ 2014;349:g4180.

5 Etheridge Z, Gatland E. When and how to discuss "do not resuscitate" decisions with patients. BMJ 2015;350:h2640.

6 Venn R. Futile CPR is tantamount to assault. BMJ 2016;352:i602.
7 Tomlinson J. My reality of do not attempt cardiopulmonary resuscitation decisions. A Better NHS [blog], 29 Jun 2014. https://abetternhs.net/2014/06/29/ my-reality-of-do-not-attempt-cardio-pulmonaryresuscitation-decisions/ (accessed 26 Feb 2017).

8 Caldwell G. Full cardiopulmonary resuscitation should not be used for ordinary dying. BMJ 2015:351:h3769.

9 Gillick MR. Advance care planning. N Eng/ J Med 2004:350:7-8.

10 Bishop JP, Brothers KB, Perry JE, et al. Reviving the conversation around CPR/DNR. Am J Bioeth 2010;10:61-7.

11 Ohlsson MA, Kennedy LM, Juhlin T, et al. Evaluation of pre-arrest morbidity score and prognosis after resuscitation score and other clinical variables associated with in-hospital cardiac arrest in southern Sweden. Resuscitation 2014;85:1370-4.

12 Rockwood K, Song X, MacKnight C, et al. A global clinical measure of fitness and frailty in elderly people. CMAJ 2005;173:489-95.

13 Breault JL. DNR, DNAR, or AND? is language important? Ochsner J 2011;11:302-6.

14 Fritz Z, Malyon A, Frankau JM, et al. The universal form of treatment options (UFTO) as an alternative to do not attempt cardiopulmonary resuscitation (DNACPR) orders: a mixed methods evaluation of the effects on clinical practice and patient care. PLoS One 2013;8:e70977.

15 Etheridge Z, Gatland E. When and how to discuss "do not resuscitate" decisions with patients. BMJ 2015;350:h2640. 